\title{
Cell Apoptosis Induced by $\delta$-Elemene in Colorectal Adenocarcinoma Cells via a Mitochondrial-mediated Pathway
}

\author{
Chun-Ying XIE, ${ }^{a}$ Wei YAng, ${ }^{c}$ Ming LI, ${ }^{e}$ Jun YInG, ${ }^{c}$ \\ Shu-Juan TAO, ${ }^{d}$ Karen Li, ${ }^{e}$ Jin-Hua DONG, ${ }^{d}$ and Xi-Sha WANG ${ }^{*, b}$ \\ ${ }^{a}$ The Sixth Affiliated Hospital, SUN YAT-SEN University, ${ }^{b}$ College of Pharmacy, Guang Dong Pharmaceutical \\ University, No. 280 Waihuan Rd., Higher Education Mega Center of Guangzhou, Guangdong, China, \\ ${ }^{c}$ Center for Drug Non-clinical Research and Evaluation of Pharmaceutical Industrial Research \\ Institute in Guangzhou, 'Department of Chemical Pharmaceutics, Shenyang Pharmaceutical \\ University, and ePrince of Wales Hospital, Chinese University of Hong Kong
}

(Received April 21, 2009; Accepted July 6, 2009)

\begin{abstract}
The chemical compound $\delta$-elemene, isolated from the Chinese herbal medicine plant Curcuma Wenyujin, has been known to exert antitumor activity. In this study we demonstrated that apoptotic cell death induced by $\delta$-elemene in DLD-1 cells was concentration-and time-dependent, and had little inhibition of the normal human liver cell line WRL-68. Apoptosis was further confirmed and quantified by DNA fragmentation ELISA, Annexin V (AnV) binding of externalized phosphatidylserine and the mitochondrial probe JC-1 using flow cytometry. The rapid increase in intracellular reactive oxygen species (ROS) levels was involved in the mechanism of cell death. Western blot analysis demonstrated that $\delta$-elemene activated the caspase-signaling pathway, leading to the proteolysis conversion of pro-caspase- 3 to activate caspase-3, and the subsequent cleavage of the caspase substrate PARP. In the process of the induction of apoptotic cell death, Bax translocated into mitochondria, a reduction in $\Delta \psi \mathrm{m}$ was observed and a release of cytochrome $c$ and apoptosis inducing factor (AIF) from mitochondria into the cytosol occurred, indicating that cell death induced by $\delta$ elemene was through a mitochondrial-mediated pathway.
\end{abstract}

Key words $-\delta$-elemene; apoptosis; mitochondria; human colorectal adenocarcinoma

\section{INTRODUCTION}

Elemene is a naturally occurring compound that can be isolated from the traditional Chinese medicinal herb Curcuma Wenyujin, which is used to treat tumors in Chinese folk medicine. ${ }^{1,2)}$ Elemene exists as an essential oil mixture of $\beta$-, $\gamma$ - and $\delta$-elemene (Fig. $1)$. The major antitumor active component, $\beta$-elemene, possesses broad-spectrum clinical activity in treatment of various tumors and is known to induce apoptosis. ${ }^{3)} \delta$-elemene is another isomeric compound of $\beta$-elemene with a different site of double bond. Our previous study was shown that $\delta$-elemene exerts antitumor activity by inducing apoptosis in Hela cells, ${ }^{4)}$ and possesses no signs of bone marrow cells and normal liver cell lines WRL-68 ${ }^{5}$ suppression.

Apoptosis, defined as programmed cell death, can be initiated by a death receptor-mediated pathway or by a mitochondria-mediated pathway. ${ }^{6}$ The death receptor pathway is initiated when a specific ligand binds to a tumor necrosis factor (TNF) receptor su-

\footnotetext{
*e-mail: yangwei0719@163.com
}

perfamily member. The mitochondrial pathway is initiated by the translocation of Bax into mitochondria. ${ }^{7)}$ This is followed by an increase in mitochondrial membrane permeability $(\Delta \psi \mathrm{m})$ and a release of cytochrome $c$ (cyto $c$ ) and apoptosis inducing factor (AIF) from mitochondria into the cytosol. In the cytosol, cyto $c$ activates post-mitochondrial caspase cascades, caspase- 3 and caspase- 9 , which leads to apoptotic cell death. ${ }^{8)}$ AIF is a caspase-independent apoptotic effector which, on translocating from the cytosol to the nucleus, causes chromatin condensation and large scale DNA fragmentation, leading to apoptotic cell death. ${ }^{9)}$

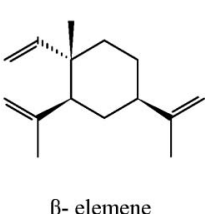

$\beta$ - elemene

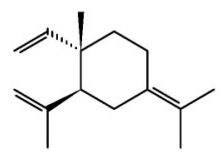

$\gamma$-elemene

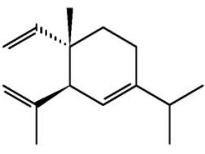

$\delta$-elemene
MW: 204.35

Fig. 1. Chemical Structure of $\beta$-Elemene, $\gamma$-Elemene and $\delta$ Elemene 
In this communication, the antitumor activity and the potential mechanisms of $\delta$-elemene were investigated. Reactive oxygen species (ROS) are constantly generated under normal conditions as a consequence of aerobic metabolism. ${ }^{10)}$ There is a growing consensus that oxidative stress and the redox state of a cell play a pivotal role in regulating apoptosis. ${ }^{11,12)}$ Oxygen free radical formation is associated with the generation and development of certain tumors. Elemene has an inhibitory effect on oxygen free radical formation in tumor cells. ${ }^{13)}$ Mitochondria are the richest source of ROS in the cell, converting $1-2 \%$ of reduced oxygen into superoxide. ${ }^{14)}$ Inhibition of the mitochondrial electron transport chain, resulting in subsequent release of ROS, is an early event in many forms of apoptosis. ${ }^{15,16)}$ Oxidative stress induces a number of downstream events in apoptosis, including aspartate-specific cysteine protease (caspase) activation and DNA fragmentation. The caspase cascade appears to be the main pathway by which cellular death is orchestrated. Poly (ADP-ribose) polymerase (PARP) is a nuclear enzyme selectively activated by DNA strand damage to participate in DNA repair. ${ }^{17)}$

In this study we explored the intracellular mechanism of $\delta$-elemene induced cell death in DLD- 1 cells, human colorectal adenocarcinoma cell line. We investigated the roles and relationships of ROS, mitochondrial in DLD-1 cells treated with $\delta$-elemene. Our results suggest that $\delta$-elemene induced apoptotic cell death in DLD-1 cells is mediated by an increase in ROS generation and the activation of caspase- 3 and mitochondria-mediated apoptosis pathways.

\section{MATERIALS AND METHODS}

Cell Lines Human colorectal adenocarcinoma cell line DLD-1 and normal human liver embryonic WRL-68 line were purchased from American Type Culture Collection (ATCC, \#CRL221, \#CL48, MD, USA). DLD-1 cells were cultured in RPMI-1640 medium supplemented with $10 \%$ fetal bovine serum (FBS; GIBCO, Invitrogen), $100 \mathrm{U} / \mathrm{ml}$ of penicillin, and $100 \mu \mathrm{g} / \mathrm{ml}$ of streptomycin (GIBCO, Grand Island, NY, USA). WRL-68 cells were cultured in $\alpha$ Minimum Essential Medium (GIBCO BRL, Rockville, MD, USA) with $10 \%$ FBS. Cells were incubated in a humidified atmosphere of $5 \% \mathrm{CO}_{2}$ in air at $37^{\circ} \mathrm{C}$.

Reagent and Cell Culture $\delta$-elemene and $\beta$-elemene were isolated from the essential oil of Curcuma Wenyujin using the method reported in reference ${ }^{1)}$ (assay $>97 \%, \mathrm{GC}$ ).

Determination of Anti-proliferation Activity Using MTT on DLD-1 Cell Lines Survival of cells was assessed using 3-(4,5-dimethylthiazol-2-yl)-2,5-diphenyltetrazolium bromide (MTT) (thiazolyl blue, Sigma, MO, USA) as previously described. ${ }^{18)}$ Briefly, DLD-1 cells were cultured to $80 \%$ confluence and then exposed to the indicated concentrations of $\delta$-elemene or $\beta$-elemene at $200 \mu \mathrm{M}$ for $12,24,48 \mathrm{~h}$. Twenty microliters of $5 \mathrm{mg} / \mathrm{ml}$ stock solution of MTT were added to each well, and incubated at $37^{\circ} \mathrm{C}$ for $4 \mathrm{~h}$, after which, $150 \mu \mathrm{l}$ of dimethyl sulfoxide (DMSO) was added to each well. The absorbance was measured using a 96-well micro-titer plate reader at $570 \mathrm{~nm}$. The percentage of cell growth inhibition was calculated as follows:

$$
\begin{aligned}
\text { Inhibition }(\%)= & {[A 570(\text { control })-A 570(\text { drug })] } \\
& / A 570(\text { control }) \times 100 \%
\end{aligned}
$$

Assessment of Cell DNA Fragmentation DNA fragmentation was determined by a DNA fragmentation ELISA kit (Roche Molecular Biochemicals, Mannheim, Germany). DLD-1 cells were cultured to $80 \%$ confluence and then exposed to different concentrations of $\delta$-elemene for the periods of time indicated. L-Glutathione (GSH) and z-DEVD-fmk were added 1 or $2 \mathrm{~h}$ prior to the treatment with $\delta$-elemene.

Flow Cytometric Detection of Annexin-V (AnV)

Apoptosis was measured using flow cytometry to quantify the levels of detectable phosphatidylserine (PS) externalization on the outer membrane of apoptotic cells. ${ }^{19)}$ Briefly, DLD-1 cells were plated at $5 \times$ $10^{4} / \mathrm{ml}$ in RPMI1640. Flasks were incubated with 200 $\mu \mathrm{M} \delta$-elemene. GSH was added $1 \mathrm{~h}$ prior to the treatment with $\delta$-elemene. Cells were harvested, suspended at $1 \times 10^{6} / \mathrm{ml}$, and washed two times with ice-cold PBS after 12, 24, $48 \mathrm{~h}$. The cells were suspended in $300 \mu \mathrm{l}$ of dilute binding buffer from an Annexin-V FITC kit (Alexis, Lausen, Switzerland), then $5 \mu \mathrm{l}$ of propidium iodide (PI) and $5 \mu$ l of Annexin-V-FITC were added. The tubes were gently mixed and kept in the dark on ice for 10 min before analysis by flow cytometry (FACScan, Becton Dickinson, San Jose, CA, USA). Data were analyzed using LYSIS II software. $\left(\mathrm{AnV}^{+}\right) \mathrm{PI}^{-}$cells were considered early apoptotic, and $\left(\mathrm{AnV}^{+}\right) \mathrm{PI}^{+}$cells were considered late apoptotic and necrotic.

Measurement of Generation of Reactive Oxygen Species Hydroperoxide and superoxide production was determined using $2^{\prime}, 7^{\prime}$-dichlorofluorescein 
and dihydroethidium (CM-H2DCFDA; Molecular Probes Inc., Eugene, OR, USA.) as described by Curtin and Donovan, ${ }^{20)}$ with some modifications. Briefly, after the treatment of cells with $200 \mu \mathrm{M}$ of $\delta$-elemene for 6,12 and $24 \mathrm{~h}, \mathrm{DLD}-1$ cells were collected by centrifugation and suspended in $200 \mu \mathrm{l}$ of RPMI medium, after which the cells were loaded with CM-H2DCFDA $(10 \mu \mathrm{M})$ for $45 \mathrm{~min}$ at $37^{\circ} \mathrm{C}$ and then washed with PBS to remove the CM-H2DCFDA. The levels of ROS were measured by flow cytometry by determining the fluorescence intensity relative to that of the control group. GSH was added $1 \mathrm{~h}$ prior to the treatment with $\delta$-elemene for $3 \mathrm{~h}$.

Mitochondrial Transmembrane Potential Measurement The mitochondrial transmembrane potential $(\Delta \psi \mathrm{m})$ was evaluated by JC-1 assay. In the treatment of cells with $200 \mu \mathrm{M}$ of $\delta$-elemene for 6,12 and $24 \mathrm{~h}, \mathrm{DLD}-1$ cells were suspended in $200 \mu \mathrm{l}$ of RPMI medium, after which JC-1 (300 nM, Molecular Probes) was added for $15 \mathrm{~min}$ incubation at $37^{\circ} \mathrm{C}$ in the dark. The cells were then harvested by trypsin $(0.25 \%)$ and washed once with PBS. Following resuspension in PBS, the cells were subjected to flow cytometry analysis. GSH was added $1 \mathrm{~h}$ prior to the treatment with $\delta$-elemene for $3 \mathrm{~h}$.

Preparation of Proteins in the Mitochondrial and Cytosolic Fractions Preparation of proteins was performed as previously described ${ }^{10)}$ with minor modifications. The cells were washed twice in ice-cold PBS and resuspended in five volumes of ice-cold extract buffer $(20 \mathrm{mM}$ Western blotting analysis Hepes$\mathrm{KOH}, 1.5 \mathrm{mM} \mathrm{MgCl} 2,1 \mathrm{mM}$ EDTA, 1 mM EGTA, 1 $\mathrm{mM}$ DTT, and $0.1 \mathrm{mM}$ phenylmethanesulfonyl fluoride (PMSF), $\mathrm{pH}$ 7.5). The resuspended cells were homogenized with 10 strokes of a Teflon homogenizer. The homogenates were centrifuged twice at $750 \mathrm{~g}$ for $10 \mathrm{~min}$ at $4{ }^{\circ} \mathrm{C}$. The supernatants were centrifuged at $10000 \mathrm{~g}$ for $15 \mathrm{~min}$ at 4 to obtain the mitochondrial pellets. Cytosolic fractions were obtained after further centrifugation at $100000 \mathrm{~g}$ for $1 \mathrm{~h}$ at $4^{\circ} \mathrm{C}$. The protein concentrations of the resulting supernatants and mitochondrial fractions were measured and stored at $-70^{\circ} \mathrm{C}$.

Western Blotting Analysis Briefly, $10 \mu \mathrm{g}$ of protein from the mitochondrial or cytosolic fraction and $40 \mu \mathrm{g}$ of total protein from treated cells were loaded onto $12 \%$ sodium dodecyl sulfate (SDS) polyacylamide gels, and the separated proteins transferred to nitrocellulose membranes (Amersham Bio- sciences, Piscataway, NJ). To detect the levels of Bax, cyto $c$ and AIF a mouse-anti-human monoclonal Bax antibody (Santa Cruz Biotechnology, Santa Cruz, CA), a mouse-anti-human monoclonal cyto $c$ antibody (BioVision Research Products, Mountain View, CA) and a mouse-anti-human monoclonal AIF antibody (Santa Cruz Biotechnology) were employed with a horseradish peroxidase-conjugated goat-antimouse IgG antibody (Santa Cruz Biotechnology). The level of cleaved caspase-3 was detected by using a goat polyclonal caspase-3 antibody (Santa Cruz Biotechnology) as the primary antibody and a polyclonal mouse-anti-goat IgG antibody as the secondary antibody both from Santa Cruz Biotechnology. The level of $85 \mathrm{kDa}$-cleaved PARP was detected using a rabbit polyclonal PARP antibody (Promega, Madison, WI) as the primary antibody and a polyclonal goat-anti-rabbit IgG antibody as the secondary antibody (Santa Cruz Biotechnology). A goat-anti-human actin antibody was used to detect the levels of actin, which was used as a control for equal loading. Detection of the target protein signal was achieved using an ECL system (Amersham Bioscences).

Statistical Analysis All results were obtained in at least three independent experiments. Data were expressed as means \pm S.D. Representative data were analyzed for statistical significance by software SPSS11.5. Differences among groups were analyzed by One-Way ANOVA, multiple comparisons used LSD and SNK's test for homogeneity of variance and Dunnett's T3-test for heterogeneity of variance. $p<$ 0.05 was considered statistically significant.

\section{RESULTS}

Inhibition of Growth of DLD-1 Cells Was Dose and Time Dependent When DLD-1 cells in culture were treated with various concentrations of $\delta$-elemene $(0-400 \mu \mathrm{M})$ for $24 \mathrm{~h}$ (Fig. 2a) or with $200 \mu \mathrm{M}$ $\delta$-elemene for indicated periods (Fig. 2b), the growth of these cells was significantly inhibited in time and dose-dependent manners. This inhibitory action was closely similar to that of $\beta$-elemene, and there was no significant difference between $\beta$-elemene and $\delta$-elemene treatment (Fig 2a). The inhibitory concentration, $50 \%\left(\mathrm{IC}_{50}\right)$ value of $\delta$-elemene and $\beta$-elemene for DLD-1 cells was $222.4 \mu \mathrm{M}$ and $206.4 \mu \mathrm{M}$, respectively, when treated for $24 \mathrm{~h}$. The IC $\mathrm{IC}_{50}$ of DLD-1 cells at 12,24 and $48 \mathrm{~h}$ was $308.4,222.4$ and $159.8 \mu \mathrm{M}$, respectively (Fig. 2b). However, the viability of nor- 
mal human cell line WRL-68 was almost unaffectted at $200 \mu \mathrm{M}$ after treatment with $\delta$-elemene (Fig. 2a) .

DNA Fragmentation in DLD-1 Cells Treated with $\delta$-Elemene $\delta$-Elemene is able to significantly induce DNA fragmentation, and the amount of fragmentation was increased in a dose-dependent manner; there was 3.8 fold increase in $200 \mu \mathrm{M} \delta$-elemene for $24 \mathrm{~h}$ with vector control cells (Fig. $3 \mathrm{c} .{ }^{* *} p<0.01 \mathrm{vs}$. control). The time course study showed that the amount of DNA fragmentation was elevated after treatment for $12 \mathrm{~h}$ ( 2.5 fold that of the vector control), and it peaked at $48 \mathrm{~h}$ (4.0 fold that of the vec-
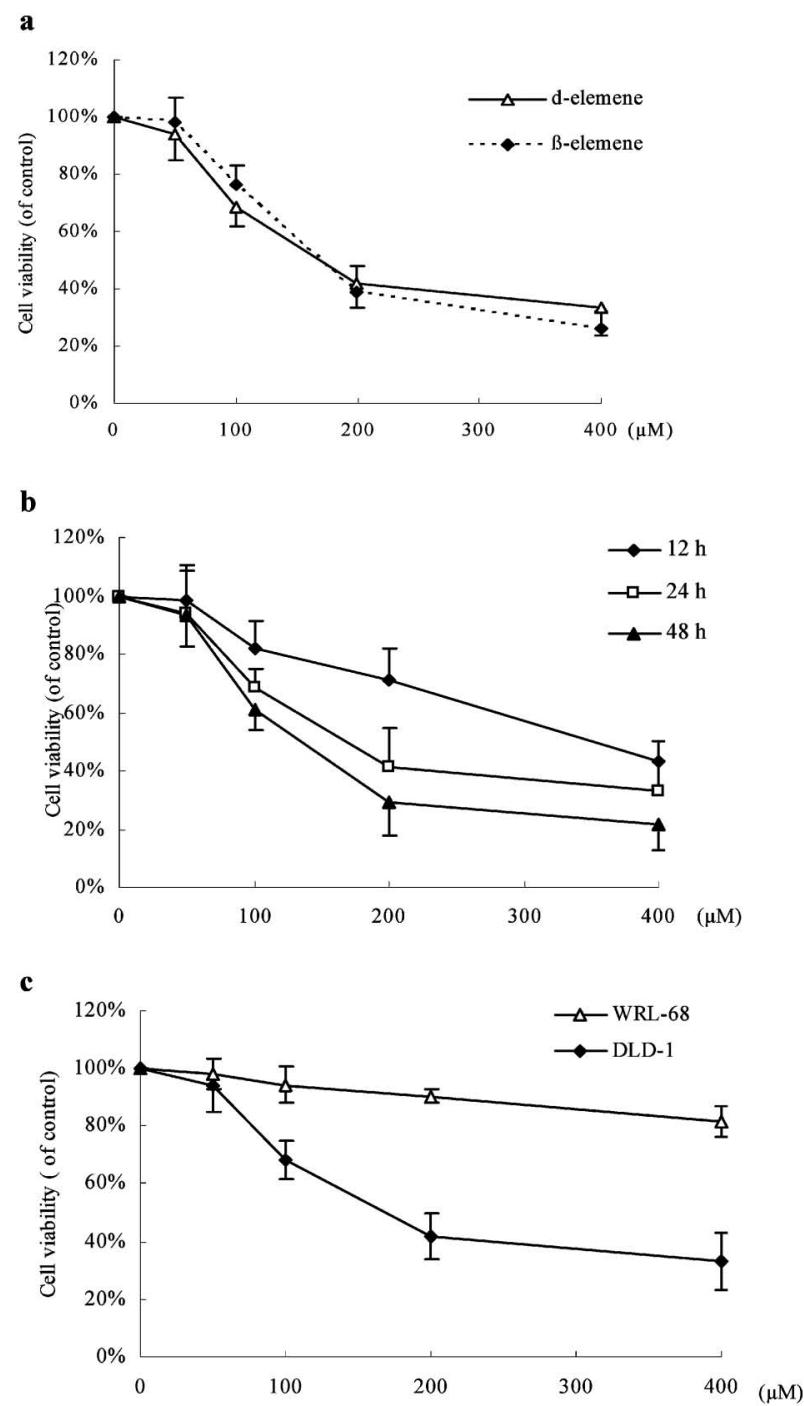

Fig. 2. Dose- and Time-dependent Inhibition of Proliferation of DLD-1 Cells by $\delta$-Elemene Treatment

(a) DLD-1 cells were treated with various doses of $\delta$-elemene and compared with $\beta$-elemene for $24 \mathrm{~h}$. (b) Cells treated with $200 \mu \mathrm{M} \delta$-elemene for various time periods. (c) Effect of $\delta$-elemene in DLD-1 cells and WRL-68 cells for $24 \mathrm{~h}$. The results shown are representative of 3 independent experiments. tor control) after treatment with $200 \mu \mathrm{M} \delta$-elemene (Fig. 3b). Furthermore, the DNA fragmentation in DLD-1 cells treated with $\delta$-elemene was inhibited by GSH or z-DEVD-fmk (Fig. $3 \mathrm{c},{ }^{\sharp} p<0.05,{ }^{\#} p<0.01$ vs. $200 \mu \mathrm{M} \delta$-elemene) for $24 \mathrm{~h}$.

Cell Death Induced by $\delta$-Elemene Was in Manner by Apoptosis Results showed that apoptosis was triggered after treatment for $12 \mathrm{~h}$ (Fig. 4a). The percentage of early apoptosis represented by $(\mathrm{AnV})^{+}$ $\mathrm{PI}^{-}$cells was significantly increased by $\delta$-elemene treatment in a time-dependent manner with $29 \%$ at 48 h (Fig. 4b). Total cell death, which comprised early apoptotic and late apoptotic cells, calculated by the
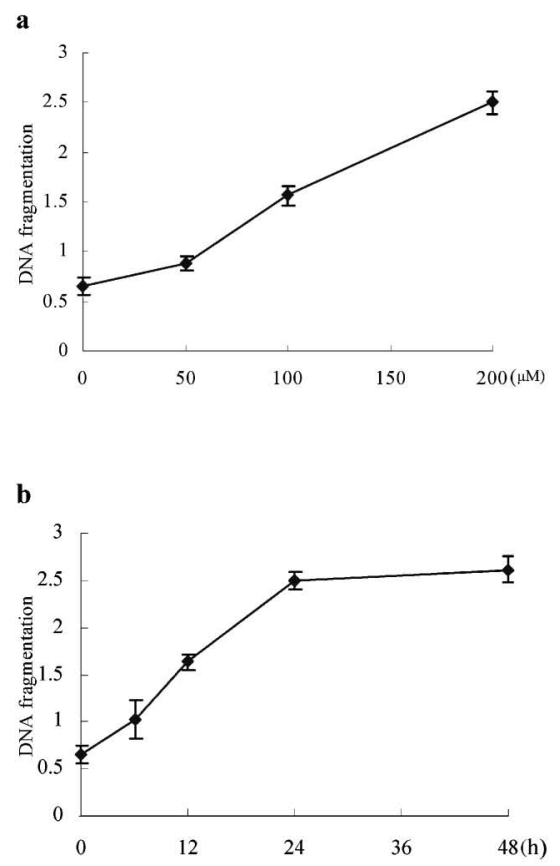

c

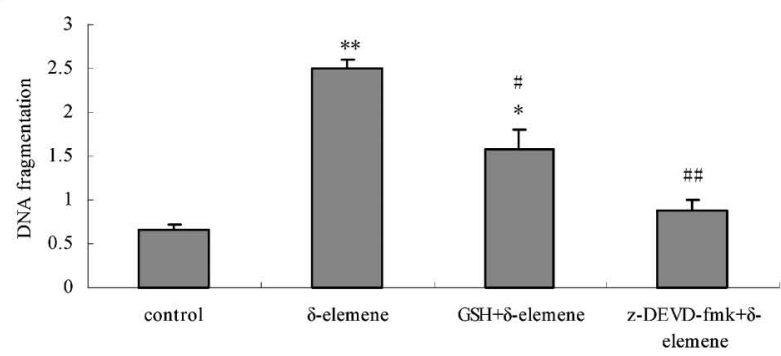

Fig. 3. Effect of $\delta$-Elemene on DNA Fragmentation in DLD-1 Cells

Cells were treated with various concentrations of $\delta$-elemene $(0-200 \mu \mathrm{M})$ for $24 \mathrm{~h}$ (a) or with $200 \mu \mathrm{M}$ of $\delta$-elemene for indicated periods (b). The DNA fragmentation was determined by cellular DNA fragmentation ELISA assay. In the experiment using GSH and z-DEVD-fmk, cells were pretreated with $1 \mathrm{mM}$ GSH or with $2 \mu \mathrm{M}$ z-DEVD-fmk 1 or $2 \mathrm{~h}$ prior to the treatment by $200 \mu \mathrm{M}$ of $\delta$-elemene for $24 \mathrm{~h}$ (c). ${ }^{* *} p<0.01 v s$. control group; $\# p<0.05$, $\# \# p<0.01$ vs. $200 \mu \mathrm{M}$ of $\delta$-elemene for $24 \mathrm{~h}$. 
summation of the $(\mathrm{AnV})^{+} \mathrm{PI}^{-}$and $(\mathrm{AnV})^{+} \mathrm{PI}^{+}$cell populations, was also increased at $24 \mathrm{~h}$. Compared with the untreated control, more death events were observed in $\delta$-elemene treated cells for $48 \mathrm{~h}$. Furthermore, the rate of early apoptosis in DLD-1 cells treated with $\delta$-elemene was inhibited by GSH or z-DEVDfmk（Fig. $4 \mathrm{c},{ }^{\sharp} p<0.01,{ }^{\# \#} p<0.001 v s .200 \mu \mathrm{M} \delta$-elemene) for $24 \mathrm{~h}$.

Cell Death Induced by $\delta$-Elemene Was Associated with an Increase in ROS Generation ROS generation in DLD-1 cells treated with $\delta$-elemene was analyzed by flow cytometry. The treatment of DLD-1 cells with $200 \mu \mathrm{M} \delta$-elemene resulted in a time-dependant increase in ROS generation (Fig. 5a). As shown in Fig. 5b, there was approximately $7.8,18.2$ or 21.8 fold increase in generation of ROS in $200 \mu \mathrm{M} \delta$-elemene for 1,3 or $6 \mathrm{~h}$ compared with vector control cells, a statistically significant increase $\left({ }^{* *} p<0.001\right.$ and $\left.{ }^{*} p<0.01\right)$. Furthermore, the change of ROS induced by $\delta$-elemene was inhibited by GSH to a level $(3.46 \%)$ that was almost as low as the untreated control $(2.11 \%)$.These results indicate that the apoptosis pathway in DLD- 1 cells by $\delta$-elemene was associated with the generation of ROS.

Mitochondria Pathway Was Involved in Cell Apoptosis Induced by $\boldsymbol{\delta}$-Elemene $\quad 1$. Reduction in $\Delta \psi \mathrm{m}$ of DLD-1 cells treated with $\delta$-elemene: To examine whether $\delta$-elemene could induce a change of $\Delta \psi \mathrm{m}$, we measured $\Delta \psi \mathrm{m}$ in DLD-1 cells treated with this compound. Following treatment with $\delta$-elemene, a reduction in $\Delta \psi \mathrm{m}$ of the cells was observed (Fig. 6a). The $\Delta \psi \mathrm{m}$ started to decrease at $6 \mathrm{~h}$ following treatment with $\delta$-elemene and the reduction occurred in a time-dependent manner. Compared with control cells, DLD- 1 cells with $200 \mu \mathrm{M} \delta$-elemene treatment for $6 \mathrm{~h}$ exhibited green JC-1 fluorescence, which is consistent with a loss of mitochondrial membrane polarization. As shown in Fig. 6b, the trends of increasing incidences of compromised $\Delta \psi \mathrm{m}$ for 6,12 or $24 \mathrm{~h}$ were $2.24 \pm 0.12,2.85 \pm 0.33,5.11 \pm 0.24$ fold with respect to the untreated control, respectively (Fig. $6 \mathrm{~b},{ }^{*} p<0.05,{ }^{* *} p<0.01$, respectively, vs. untreated control, $n=3)$.

2. Translocation of Bax to mitochondria in DLD-1 cells treated with $\delta$-elemene: Translocation of Bax to mitochondria can alter the outer mitochondrial membrane permeability. It allows the release of pro-apoptotic proteins such as cyto $c$ and AIF into the cytosol. To test whether the apoptosis-inducing effect of $\delta$-ele- mene was related to the translocation of Bax into mitochondria, we determined the level of Bax in the mitochondrial fraction of DLD-1 cells treated with $\delta$ elemene by Western blot. As shown in Fig. 7, the level of Bax in mitochondria of DLD-1 cells treated with $\delta$ elemene increased in a time dependent manner, implying that the translocation of Bax into mitochondria was involved in cell death induced by $\delta$-elemene.

3. Release of cyto $c$ and AIF from mitochondria into the cytosol in $\delta$-elemene-treated DLD-1 cells: DLD-1 cells were treated with $200 \mu \mathrm{M}$ of $\delta$-elemene for various determined periods of time (Fig. 7). Analysis of cyto $c$ and AIF in the cytosol by Western blot than showed that the $\delta$-elemene levels in these cells had increased in a time dependent manner (Fig. 7). This implies that after $\delta$-elemene treatment, the release of cyto $c$ and AIF from mitochondria into the cytosol was involved in cell death induced by $\delta$-elemene.

Activation of Caspase-3 and Cleavage of PARP Were Involved in Cell Death Induced by $\delta$-Elemene

The caspase signaling pathway has been demonstrated to play a central role in cellular apoptosis. The reduction of procaspase- 3 indicates the activation of caspase-3. Two hundred $\mu \mathrm{M}$ of $\delta$-elemene was able to cleave procaspase-3 $(32 \mathrm{kDa})$ to activate caspase-3 after treatment for $12 \mathrm{~h}$ in Fig. 8a. PARP, acting intranuclearly to repair damaged DNA, is one of the substrates of activated caspase. As shown in Fig. 8a, $200 \mu \mathrm{M} \delta$-elemene was able to cleave intact PARP $(116 \mathrm{kDa})$ into an $85 \mathrm{kDa}$ fragment after treatment for $6 \mathrm{~h}$ in a time-dependent manner. The reduced level of procaspase- 3 and elevated level of cleaved PARP were much more significant than that of the untreated cells in Fig. 8.

\section{DISCUSSION}

Recently, the exploration for non-cytotoxic antitumor drug has been a major trend in the international medicine area. The cytotoxicity of elemene has been determined in various tumor cell lines in vitro. ${ }^{21,22)}$ The $\mathrm{IC}_{50}$ of elemene for normal peripheral blood leukocytes is $1.244 \mathrm{mM} .^{23)}$ The present study showed that $\delta$-elemene inhibited DLD-1 cell growth in a time- and dose- dependent manner. The $\mathrm{IC}_{50}$ values of $\delta$-elemene and $\beta$-elemene in DLD-1 cells were $222.4 \mu \mathrm{M}$ and $206.4 \mu \mathrm{M}$, respectively, and were similar to the $\mathrm{IC}_{50}(182.4 \mu \mathrm{M})$ of elemene for DLD-1 cells. ${ }^{24)}$ In this study the effect of $\delta$-elemene was com- 
$\mathbf{a}$

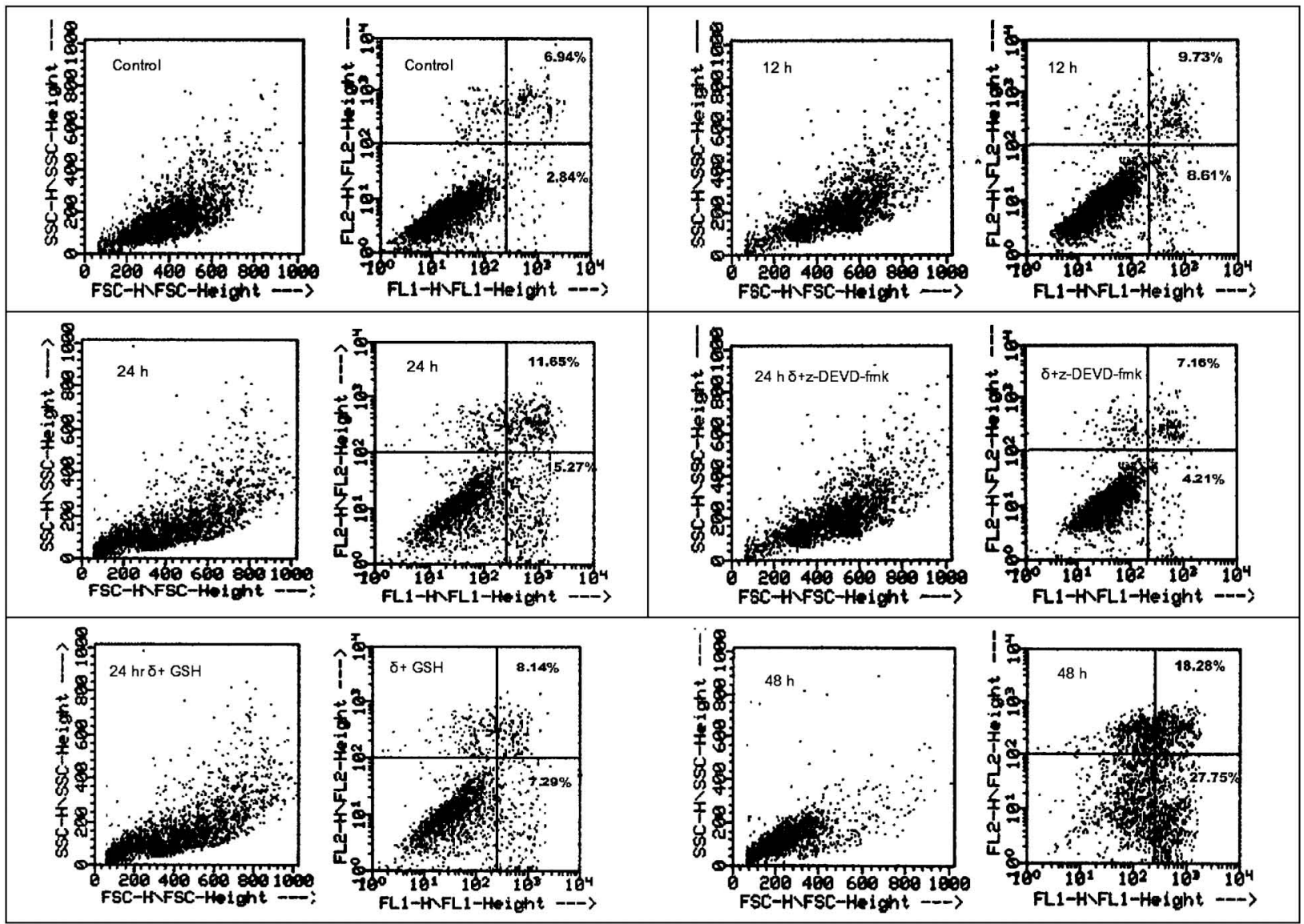

b

c
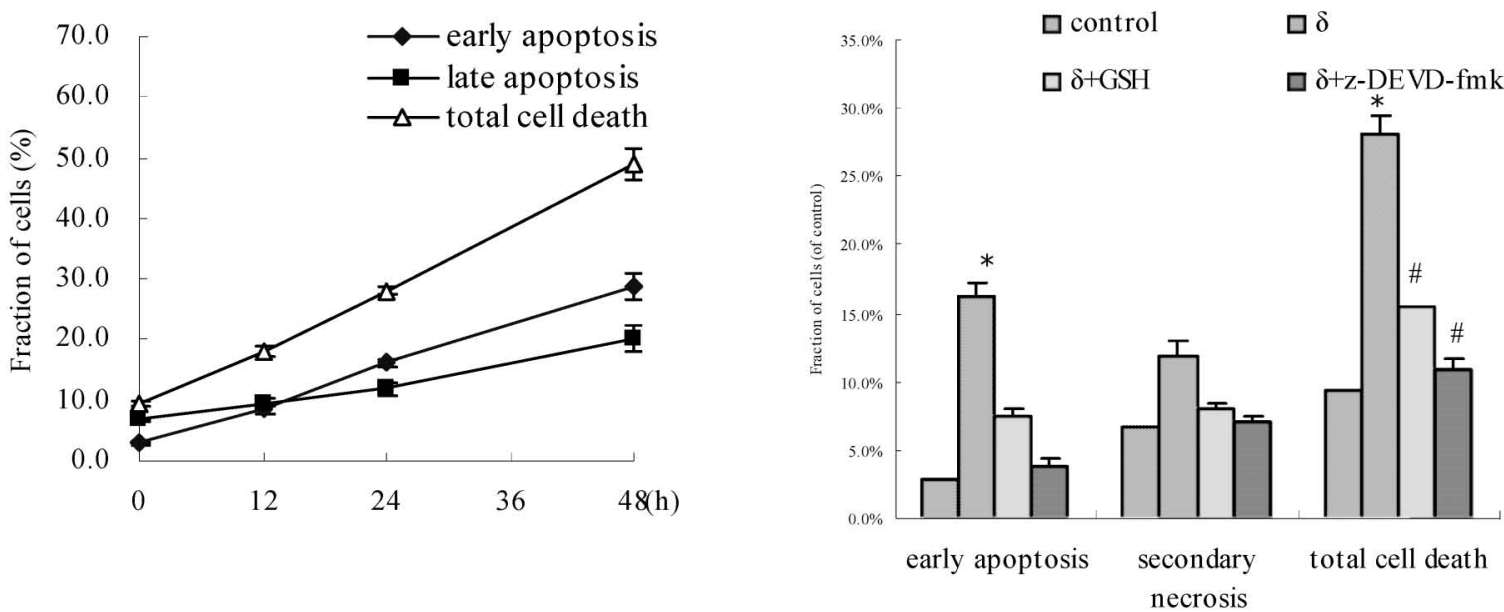

Fig. 4. Apoptosis and Necrosis in DLD-1 Cells Treated with $\delta$-Elemene

DLD-1 cells were cultured with $200 \mu \mathrm{M}$ of $\delta$-elemene for indicated time, and stained with FITC-conjugated Annexin V (AnV) and PI, followed by flow cytometric analysis. (a) The light scattering and staining profiles of a representative experiment as shown in panels I and II. Numerals in the quadrants indicate the percentages of cells in that particular quadrant with respect to total. Early apoptotic populations are found in the lower-right quadrants, while necrotic or late apoptotic cells are localized in the upper-right quadrant. (b) The percentage of early apoptosis, late apoptosis and total cell death in DLD-1 cells with treatment of $200 \mu \mathrm{M} \delta$ elemene for indicated periods. (c) The percentage of early apoptosis, late apoptosis and total cell death in DLD-1cells with treatment of $200 \mu \mathrm{M} \delta$-elemene, GSH or z-DEVD-fmk. For the experiment using GSH and z-DEVD-fmk, DLD-1 cells were pretreated with $1 \mathrm{mM} \mathrm{GSH}$ or with $2 \mu \mathrm{M} \mathrm{z}$-DEVD-fmk 1 or $2 \mathrm{~h}$ prior to the treatment by $200 \mu \mathrm{M}$ of $\delta$-elemne for $24 \mathrm{~h}$. Values represent mean \pm S.D. of 3 independent experiments performed. ${ }^{*} p<0.01,{ }^{* *} p<0.001 v s$. control; ${ }^{*} p<0.01 v s .200$ $\mu \mathrm{M} \delta$-elemene. 
$\mathbf{a}$

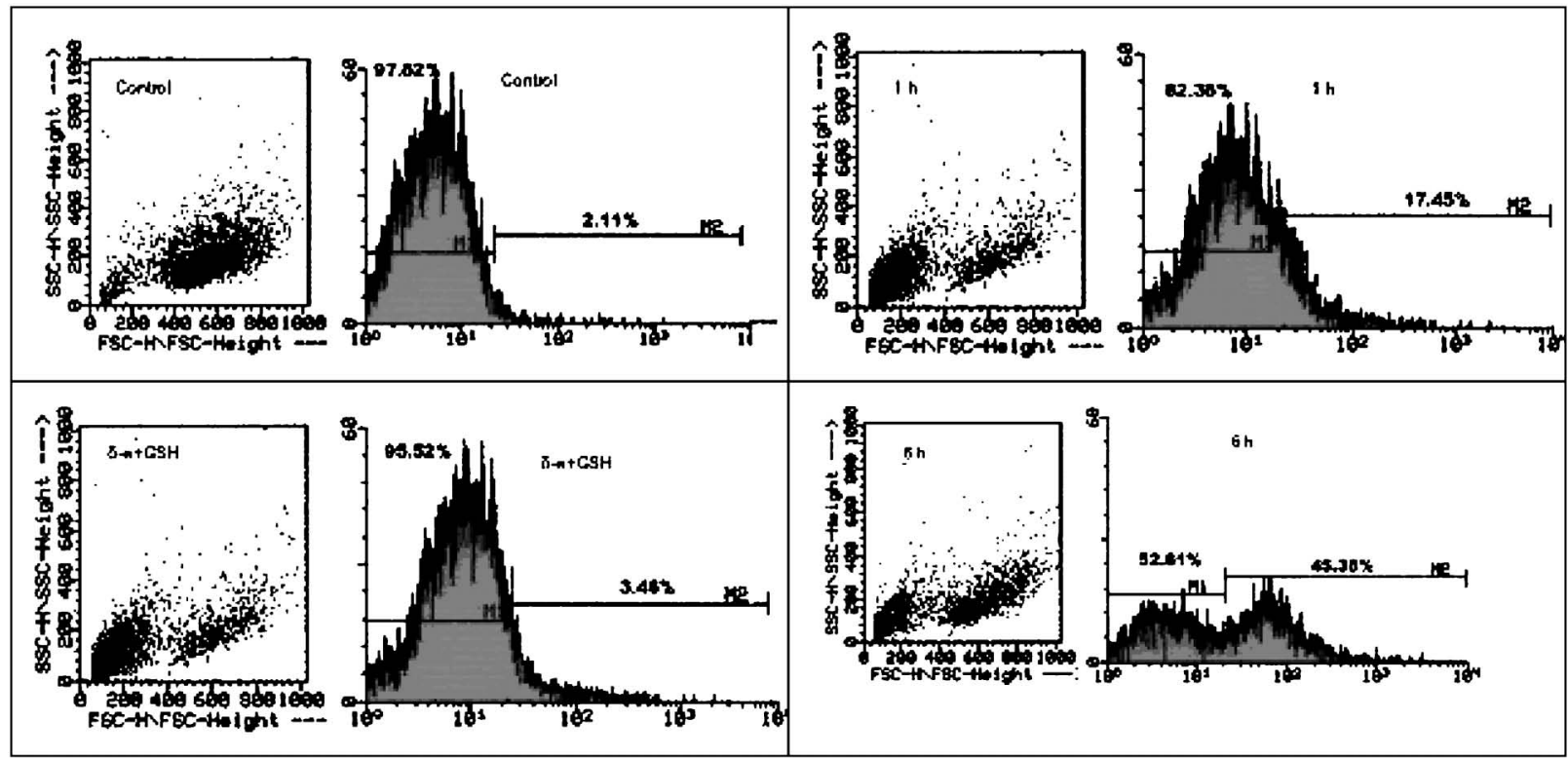

b

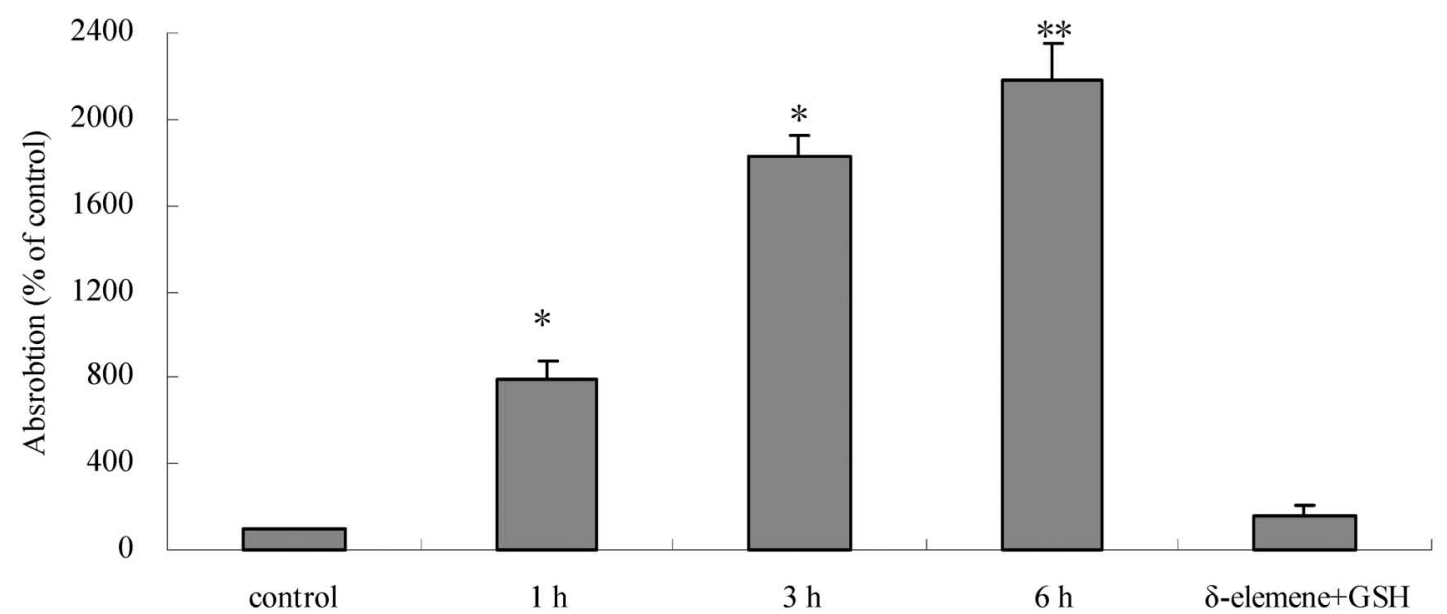

Fig. 5. The Increase in ROS Generation Related to Cell Apoptosis Induced by $\delta$-Elemene in DLD-1 Cells

Cells were treated with $200 \mu \mathrm{M}$ of $\delta$-elemene for 1,3 and $6 \mathrm{~h}$. After treatment, cells were stained with $10 \mu \mathrm{M} \mathrm{CM}-\mathrm{H} 2 \mathrm{DCFDA}$ for 45 min at $37^{\circ} \mathrm{C}$ and analyzed by flow cytometry (a). The horizontal axis shows the relative fluorescence intensity, and the vertical axis shows cell numbers. In the experiment of inhibition by GSH on the generation of ROS, DLD-1 cells were pretreated with $1 \mathrm{mM} \mathrm{GSH} 1 \mathrm{~h}$ prior to the treatment with $200 \mu \mathrm{M}$ of $\delta$-elemene for $3 \mathrm{~h}$. The results shown are representative of three independent experiments. The data represent a mean of three independent experiments. ${ }^{* *} p<0.001$ and ${ }^{*} p<0.01$, compared with control.

pared between several tumor cell lines and a normal human liver embryonic cell by MTT assays. It appears that the growth inhibitory effect of $\delta$-elemene on DLD-1 cells is much stronger than that on normal liver cells. ${ }^{5)} \delta$-elemene has no significant inhibitory action on normal cells, and it is suggested that $\delta$-elemene may be a new non-cytotoxic compound.

DNA fragmentation, PS externalization and the loss of $\Delta \psi \mathrm{m}$ are indication that the DLD-1 cell death with $\delta$-elemene are in an apoptosis manner.

ROS production frequently occurs in response to various stimuli. In many experimental situations, the induction of apoptosis is accompanied by a rise in intracellular ROS. ${ }^{25)}$ Furthermore, the observed inhibition of apoptosis by different antioxidants such as NAC, ${ }^{25,26)}$ ascorbate ${ }^{27)}$ and $\alpha$-tocopherol ${ }^{27)}$ suggests that ROS production plays an important role in apoptosis in diverse cell lines. Our results showed that ROS were involved in apoptosis in DLD-1 cells by $\delta$-elemene. Further, it was noted that the DNA fragmentation in DLD-1 treated with $\delta$-elemene was inhibited by GSH (Fig. 3c), that GSH could attenuate early 
a

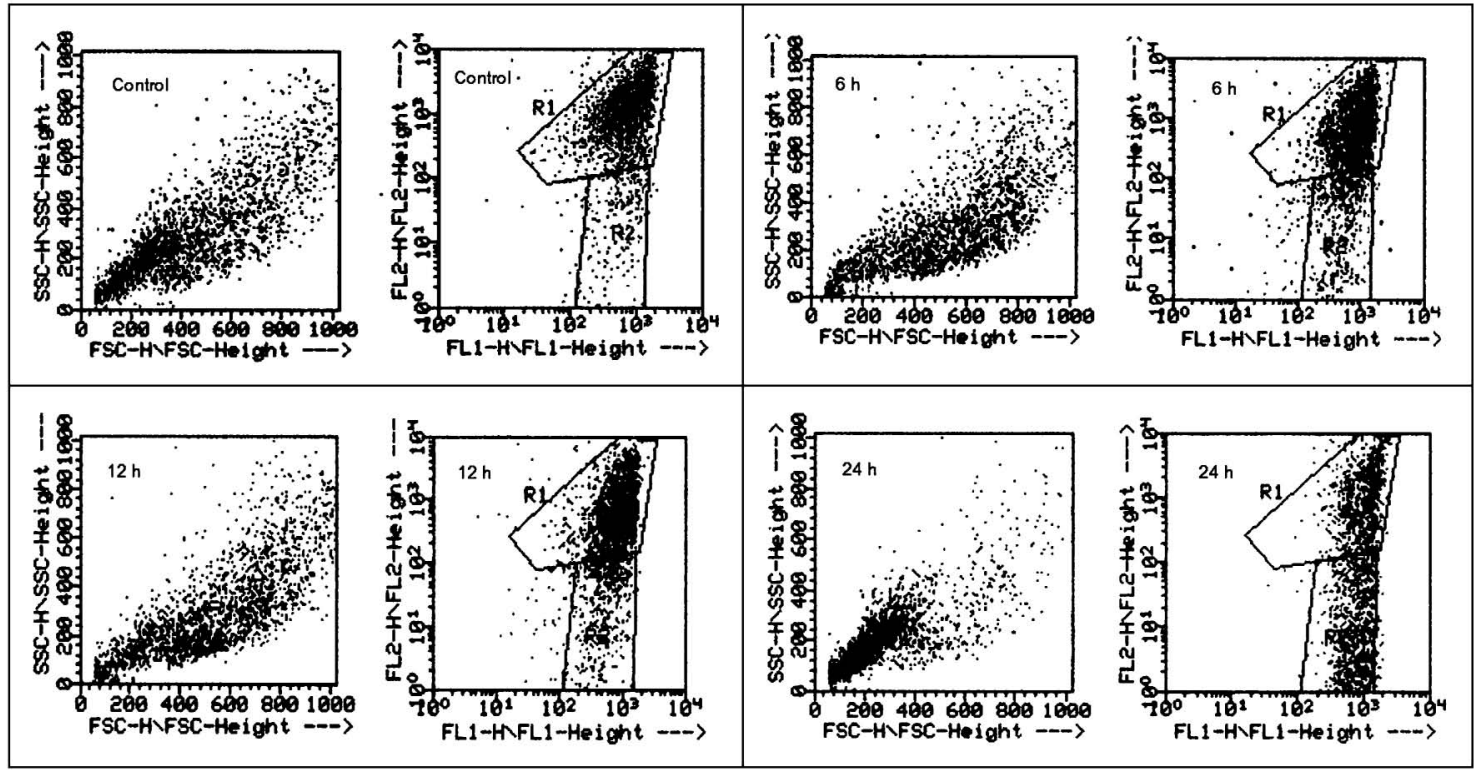

b

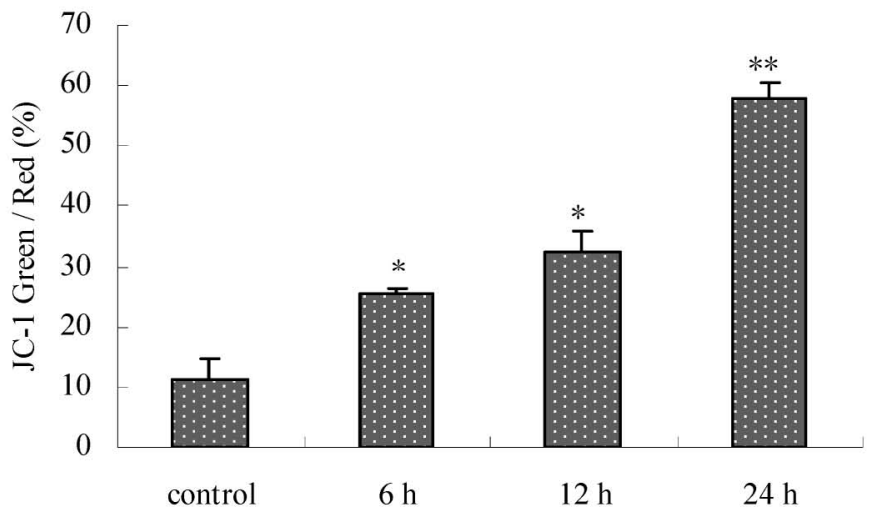

Fig. 6. Reduction in $\Delta \psi \mathrm{m}$ of DLD-1 Cells Treated with $\delta$-Elemene

Cells were treated with $200 \mu \mathrm{M}$ of $\delta$-elemene for 6,12 , and $24 \mathrm{~h}$. After treatment, cells were stained with $\mathrm{JC}-1$ for $15 \mathrm{~min}$ at $37^{\circ} \mathrm{C}$ and analyzed by flow cytometry. (a) After $\delta$-elemene treatment, depolarization of $\Delta \psi \mathrm{m}$ became evident as indicated by increased cell population in R2. Cells found in region R1 had few scattering properties typical of apoptosis. (b) The mean and SD of the results were obtained from three independent experiments. Mitochondrial damage was most marked at $24 \mathrm{~h}$ post $\delta$-elemene treatment. $\left({ }^{*} p<0.05,{ }^{*} p<0.01\right)$.

apoptosis and induced late apoptosis (Fig. 4c), and the elevation of ROS level could be inhibited by GSH (Fig. 5b). Moreover, $\delta$-elemene-induced apoptosis was reduced to a level almost as low as the control by GSH, indicating that ROS play a critical role in apoptosis in DLD-1 cells by $\delta$-elemene.

Caspases involved in apoptosis are generally divided into two categories: the initiator caspases, which include caspase-2,-8,-9 and -10 , and the effector caspases, which include caspase-3,-6, and -7.28) Active caspase- 3 consists of 17 and $12 \mathrm{kDa}$ subunits which are derived from a $32 \mathrm{kDa}$ proenzyme (pro- caspase-3). The caspase- 3 antibody recognizes both the $32 \mathrm{kDa}$ pro-caspase- 3 and the $17 \mathrm{kDa}$ subunit of active caspase-3. ${ }^{29)}$ In the present study, $\delta$-elemene was able to activate caspase- 3 in a time-dependent manner by cleaving pro-caspase-3 $(32 \mathrm{kDa})$ to active caspase-3 $(17 \mathrm{kDa})$.

AIF is a caspase-independent death effector which, in the induction of apoptosis, translocates from the mitochondrial intermembrane to the nucleus via the cytosol and causes chromatin condensation and fragmentation of DNA into $50 \mathrm{~kb}$ fragments. ${ }^{9)}$ In contrast to cyto $c$, AIF does not appear to require the 
$\mathbf{a}$

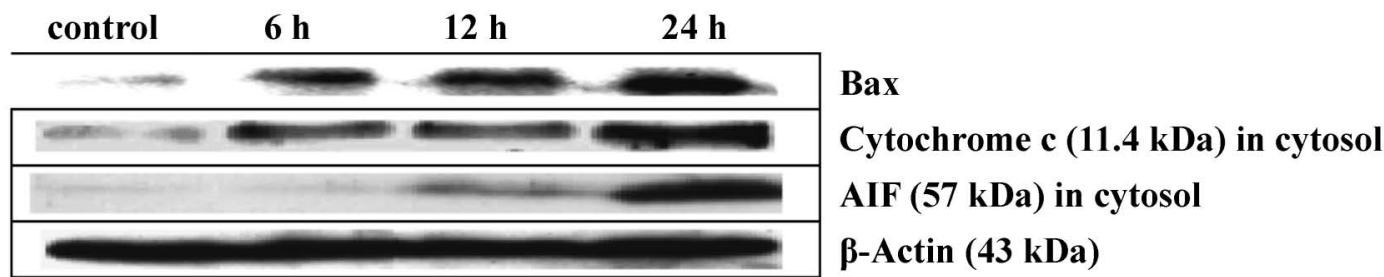

b

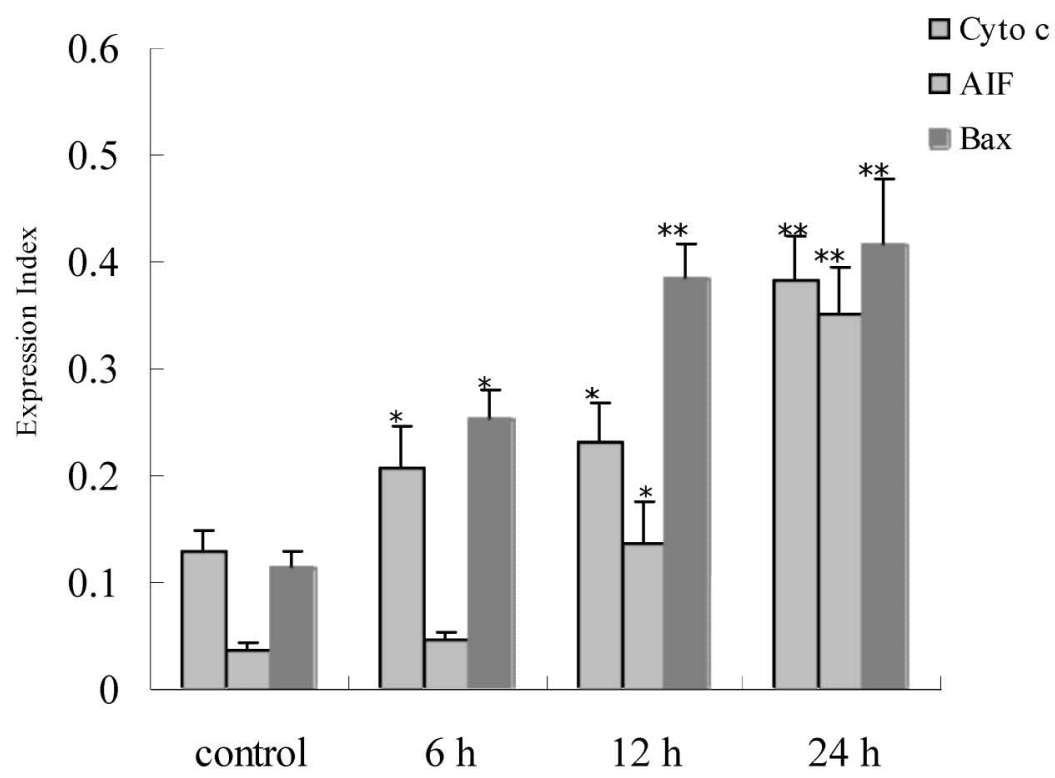

Fig. 7. Effect of $\delta$-Elemene on Bax, Cytochrome $c$ and AIF Release from Mitochondria in DLD-1 Cells

Translocation of Bax into mitochondria and the release of cyto $c$ and AIF from mitochondria into the cytosol in DLD-1 cells treated with $\delta$-elemene. DLD-1 cells were treated with $200 \mu \mathrm{M}$ of $\delta$-elemene for indicated periods up to $24 \mathrm{~h}$. After treatment, mitochondrial and cytosolic fractions were extracted. (a) The levels of Bax in the mitochondrial fraction and the levels of cyto $c$ and AIF in the cytosolic fractions were analyzed by Western blot analysis. (b) The mean and S.D. of the results were obtained from three independent experiments. $\left({ }^{*} p<0.05,{ }^{* *} p<0.01\right)$.

presence of further cytosolic factors to induce apoptotic features in the nucleus. ${ }^{9,30,31)}$ In the present study, we found that both AIF and cyto $c$ were released from mitochondria into the cytosol in DLD-1 cells treated with $\delta$-elemene. These findings suggested that $\delta$-elemene induced apoptosis in both caspase dependent and caspase-independent pathways ensuring efficient DNA breakdown. On the other hand, AIF migrates into the nucleus and induces high-molecularmass DNA fragmentation and marginal chromatin condensation. Therefore, the apoptotic phenotype and cell death observed in DLD-1 cells apparently results from the combined action of caspases and AIF.

Mitochondria respond to multiple death stimuli including those in which pro-apoptotic Bcl-2 family proteins such as Bax and Bak induce mitochondrial membrane permeabilization to cause the release of apoptotic molecules into the cytosol. ${ }^{32,33)}$ Our study showed that $\delta$-elemene elevated the level of Bax in mitochondria, and that this was followed by a release of cyto $c$ and AIF from motochondria into the cytosol, and by a reduction in the mitochondria membrane potential. Our study also showed that apoptotic cell death was induced when caspase-3 was activated and PARP cleaved.

In summary, this study suggests that $\delta$-elemene is a potent antitumor compound which is able to induce the death of human colorectal adenocarcinoma cells. The apoptosis induced by $\delta$-elemene was clearly confirmed by the features of cell death which are antiproliferation, DNA fragmentation and PS externali- 
$\mathbf{a}$

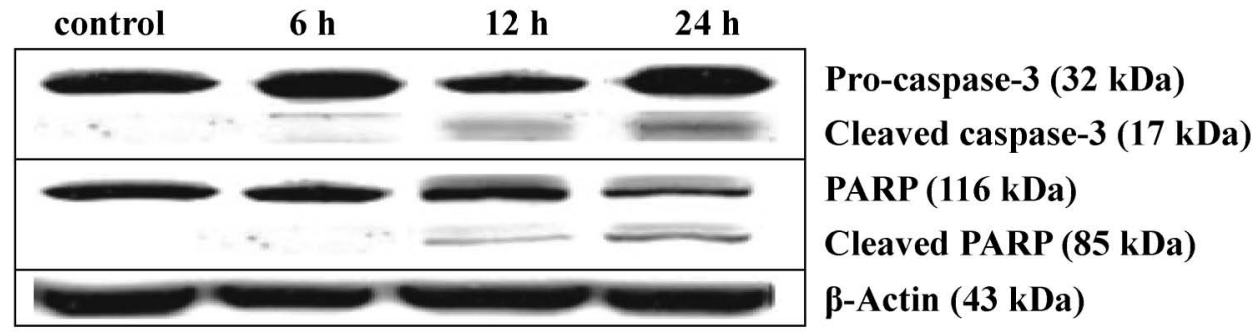

b

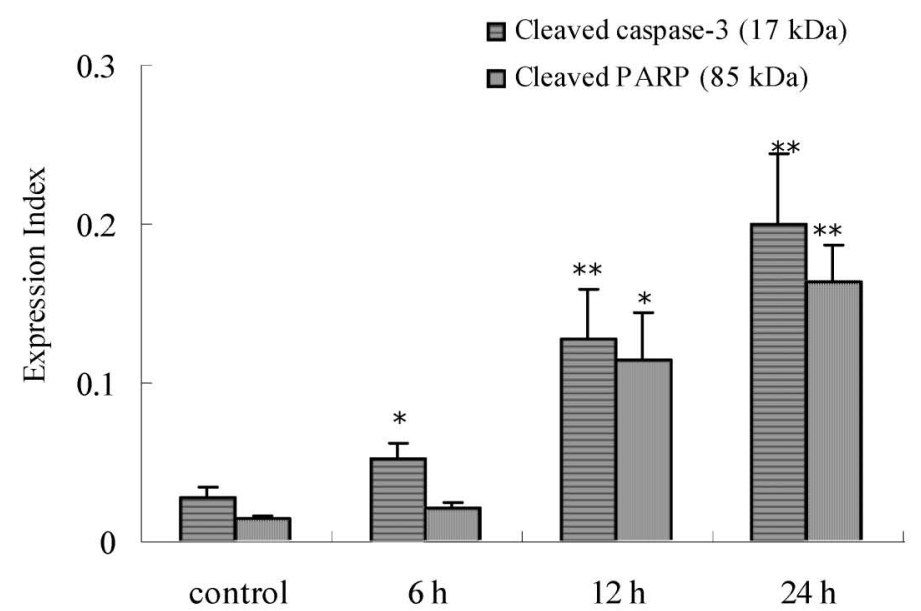

Fig. 8. Time Course of Caspase-3 Activation, PARP Cleavage in DLD-1 Cells

DLD-1 cells were treated with $200 \mu \mathrm{M} \delta$-elemene for indicated periods. (a) The levels of procaspase- 3 and $85 \mathrm{kDa}$ cleaved PARP fragment in total protein extract were analyzed by Western blot. (b) The mean and S.D. of the results were obtained from three independent experiments. $\left({ }^{*} p<0.05,{ }^{* *} p<0.01\right)$.

zation. Cell death induced by $\delta$-elemene is through mitochondria caspase-dependent and caspase-independent pathways. The increase in ROS generation and pro-caspase- 3 activation and cleaved PARP are also involved in the mechanism of $\delta$-elemene-induced cell death. The potential application of this compound in cancer cell apoptosis warrants further elucidation.

\section{REFERENCES}

1) Guo Y. T., Wu X. Y., Chen Y. L., Bull. Chin. Med., 8, 31-34 (1983).

2) Zheng S., Yang H., Zhang S., Wang X., J. Cell Biochem., 67, 106-112 (1998).

3) Yang H, Wang X. P., Yu L. L., Chinese Journal of Cancer Research, 9, 83-88 (1997).

4) Wang X. S., Yang W., Tao S. J., YAKUGAKU ZASSI, 126, 979-990 (2006).
5) Wang X. S., Yang W., Wang M. W., Zhong hui yiyao zazhi, 6, 841-843 (2006).

6) Gupta S., Life Sci., 69, 2957-2964 (2001).

7) Gross A., McDonnell J. M., Korsmeyer S. J., Genes Dev., 13, 1899-1911 (1999).

8) Eldering E, Mackus W. J., Derks I. A., Eur. J. Immunol., 34, 1950-1960 (2004).

9) Susin S. A., Lorenzo H. K., Zamzami N., Nature, 397, 441-446 (1999).

10) Liu Z. M., Chen G. G., Vlantis. A. C., Apoptosis, 10, 1345-1356 (2005)

11) Lafon C., Mathieu C., Guerrin M., Cell Growth Differ., 7, 1095-1104 (1996).

12) Bladier C., Wolvertang E. J., Cell Growth Differ., 8, 589-598 (1997).

13) Xu H. S., Li J., Liu J., Chin. J. Clin. Oncol., 23, 527-529 (1996).

14) Richter C., Gogvadze V., Biochim. Biophys. 
Acta, 1271, 67-74 (1995).

15) Hug H., Strand S. J. Biol. Chem., 272, 2819128193 (1997).

16) Castedo M., Macho A. Eur. J. Immunol., 25, 3277-3284 (1995).

17) Chambon P., Weill J. D., Biochem. Biophys. Res. Comm., 11, 39-43 (1963).

18) Zhang K., Mack P., Mol. Pharmacol., 59, 837 -843 (2001).

19) Evens A. M., Prachand S., Shi B., Clin. Cancer Res., 10, 1481-1491 (2004).

20) Curtin J. F., Donovan M., J. Immunol. Methods, 265, 49-72 (2002).

21) $\mathrm{Hu}$ J, Jin W, Yang P. M., Zhonghua Zhong Liu Za Zhi 26, 268-270 (2004).

22) Zhou H. Y., Shen J. K., Ai Zheng 22, 959-963 (2003).

23) Tao L., Zhou L., Zheng L. Y., Cancer Chemother. Pharmacol., 58, 24-34 (2006).

24) Wang X. W., Drugs of the Future, 23, 266-
270 (1998).

25) Lafon C, Mathieu C, Guerrin M. A., Cell Growth Differ., 7, 1095-1104 (1996).

26) Wu Y. J., Muldoon L. L., Neuwelt E. A., J. Pharmacol. Exp. Ther., 312, 424-431 (2005).

27) Barroso M. P., Gomez-Diaz C., Lopez-Lluch G., Arch. Biochem. Biophys., 343, 243-248 (1997).

28) Shi Y., Mol. Cell, 9, 459-470 (2002).

29) Krajewska M., Wang H. G., Cancer Res., 57, 1605-1613 (1997).

30) Plesnila N., Zhu C., Culmsee C., Groger M., J. Cereb. Blood Flow Metab., 24, 458-466 (2004).

31) Cande C., Vahsen N., Kouranti I., Oncogene, 23, 1514-1521 (2004).

32) Gross A, McDonnell J. M., Korsmeyer S. J., Genes Dev, 13, 1899-1911 (1999).

33) Ruffolo S. C., Breckenridge D. G., Nguyen M., Cell Death Differ., 7, 1101-1108 (2000). 